\title{
Healthy Places, Healthy People: Living Environment Factors Associated with Physical Activity in Urban Areas
}

\author{
Helena Nogueira, Cristina Padez and Maria Miguel Ferrão \\ University of Coimbra \\ Portugal
}

\section{Introduction}

The final years of the 20th century were characterised by the emergence of new sociodemographic profiles in which behaviour-related diseases were increasingly prominent. Societies have now recognised the fundamental role that health-related behaviours - e.g., diet, tobacco consumption and physical activity - play in human health and chronic disease risk. Everywhere, modern societies are becoming more and more sedentary, a trend contributing to the rise in rates of chronic and degenerative diseases such as type 2 diabetes, CVD, hypertension, some types of cancer, musculoskeletal diseases and high blood pressure and cholesterol. Moreover, it appears that sedentary lifestyles also cause a decline in psychological well-being, thereby increasing the risk of mental disorders (Nusselder et al. 2008).

According to the World Health Organization, 1.9 million deaths globally are caused by physical inactivity (WHO, 2002), including 600,000 in the WHO European Region. In Canada, more than two-thirds of deaths share physical inactivity as a behavioural risk (ACPHHS, 2005). In addition to being one of the main underlying causes of death in developed countries, sedentary lifestyles are a powerful contributor to the new epidemic of the $21^{\text {st }}$ century: obesity.

Obesity has increased globally since 1980 (Finucane et al. 2011); its prevalence has tripled in the last 25 years, making it a major public health concern. Among European adults, it is estimated that excess weight accounts for $50 \%$ of hypertension cases, $33 \%$ of strokes, and $25 \%$ of osteoarthritis (Mladovsky et al., 2009). According to WHO, the current trend, if it continues, will decrease life expectancy by five years by 2050 (WHO Regional Office for Europe, 2007). Portugal has one of the most worrisome situations in the EU, with excessive weight and obesity affecting 50\% of adults as of 2006 (ACS, 2008) and 31,5\% of children (Padez et al., 2004). How do we explain this trend? Researchers are in agreement that weight gain is of complex multifactorial causation. Although there may be a significant genetic component, it does not explain the recent escalation in cases (Cohen et al., 2006). Environmental factors are increasingly considered to be obesogenic, as they facilitate the excessive intake of calories and/or discourage the expenditure of energy in daily life (GilesCorti and Donovan, 2003; Portinga, 2006). 
When analysing physical activity levels across the EU, a pattern of southern disadvantage clearly emerges. The prevalence of individuals who report no physical activity within any monthly period ranges from $4 \%$ in Finland to $66 \%$ in Portugal, the highest value in the EU, followed by Italy (58\%) and Greece (57\%). Men tend to have higher physical activity levels than women, and time spent exercising shows a negative correlation with age. The percentage of individuals reporting that they exercise once a week is $60 \%$ for individuals age 15 to 25 but only $28 \%$ for individuals over 55 (Mladovsky et al., 2009). Furthermore, socioeconomic differences in physical activity consistently have been reported, with the more educated being, in general, more active (Gidlow et al., 2006). Some studies have even pointed to the emergence of more differentiated and nuanced patterns that vary by gender and types of physical activity (Demarest et al., 2007).

\subsection{Linking sedentary lifestyles to the local environment (via social structure): A socio-ecological approach}

General variations in physical activity between countries occur along with specific and differential patterns within countries, emerging from a complex web of causation. A great deal of social science research finds that health-related behaviours are partly a function of an individual's characteristics and local context (Jen et al., 2009). For example, poor people are more likely to be sedentary, and poor people living in disadvantaged areas are more likely to be sedentary than their counterparts living in more advantaged areas. Researchers have hypothesised that disadvantaged people tend to be less active because they have less leisure time, due to their occupations. Further, disadvantaged people tend to be less active in their leisure time because they are less able to afford and access exercise programmes and facilities. Finally, disadvantaged people are more likely to live in areas that discourage physical activity, e.g., homogeneous, non-mixed land-use neighbourhoods, with crime and road safety problems.

The literature has burgeoned in recent years with theoretical models and frameworks to explain socioeconomic inequalities in health-related behaviours (McNeill et al., 2006; Kamphius et al., 2007; Stafford et al., 2007; Maddison et al., 2009). Throughout these studies, most authors highlight similar pathways - e.g., socioeconomic, psychosocial and cultural that link socioeconomic status (SES), the environment and health-related behaviours.

The present study presents a framework that attempts to clarify plausible pathways to sedentary lifestyles, highlighting the contextual determinants of physical activity. The premise is that, beyond individual characteristics, contextual factors can facilitate or impede the individual's opportunity to lead a healthy, active life. The framework encompasses five main categories of determinants of physical activity that are structured and operate at different contextual levels: (A) a micro (neighbourhood) level and (B) a meso/macro level.

\subsubsection{Micro-level (neighbourhood) environmental conditions}

a. Geographical/physical circumstances: these factors stress the availability and accessibility of products, facilities or opportunities that promote or impede active lifestyles. Empirical evidence suggests that active living can be affected by population density, street connectivity, land use (access to residence, work, school, shops, food, 
leisure, sports and other amenities), pedestrian and cycling conditions (pavements, sidewalks and bicycle paths) and, in general, pleasant surroundings (Frank et al., 2004; Cerin et al., 2007; Frank et al., 2007; Leslie et al., 2007).

b. Social circumstances, including safety: social deprivation, lack of social support, lack of social capital, weak social control, violence and generally unsafe conditions can place constraints on individual choices (McNeill, 2006) and are key determinants of an individual's level of physical activity (Catlin et al., 2003; Cohen et al., 2006; Kim et al., 2006; Burdette \& Hill, 2008).

c. Psychosocial and cultural circumstances: behaviours and decisions can be influenced not only by physical and social environmental conditions but also by perceptions of those conditions, by culture-specific lifestyles patterns, by the person's general values, his or her sense of belonging and by neighbourhood connectedness. These factors may modify the individual's interaction with his or her environment. It is also likely that psychological disorders (e.g., depression, anxiety, stress or social isolation) have a detrimental effect on one's willingness to engage in formal physical activity (Wilkinson, 1999) and that psychological conditions decrease one's levels of informal physical activity (i.e., activity related to social interactions and social contacts).

d. Socioeconomic circumstances: these are circumstances that can affect levels of physical activity through any of the conditions mentioned above. People of lower SES have limited resources with which to participate in indoor activities at gymnasiums and health clubs (Wilkinson, 1999; Wilkinson \& Marmot, 2003). Beyond these constraints, people with low SES are confronted daily with social and work environments characterised by deprivation (absolute and relative), strain or lack of control over social and work life and lack of leisure time - all of which have psychological consequences, including insecurity, anxiety, stress, social isolation and depression (Wilkinson \& Marmot, 2003).

\subsubsection{Meso/macro-level environmental conditions}

e. Political circumstances: levels of physical activity may be influenced by changes in transportation planning and policies (e.g., policies that emphasise collective and active transport), zoning and urban planning (land use policies and urban design) (Maddison et al., 2009). Conditions at this level also encompass campaigns and interventions to support behaviour change.

Assuming that one's level of physical activity is determined contextually (and thereby dependent on local environments), the purpose of this paper is to analyse and understand the "obesogenic environment" in the Lisbon Metropolitan Area (LMA) by identifying micro-level neighbourhood conditions that are associated with increased individual physical activity.

\section{Data and methods}

\subsection{Study area}

This study focused upon the Lisbon Metropolitan Area (LMA), Portugal, located in the central-southern part of the country, on either side of the River Tagus (figure 1). 


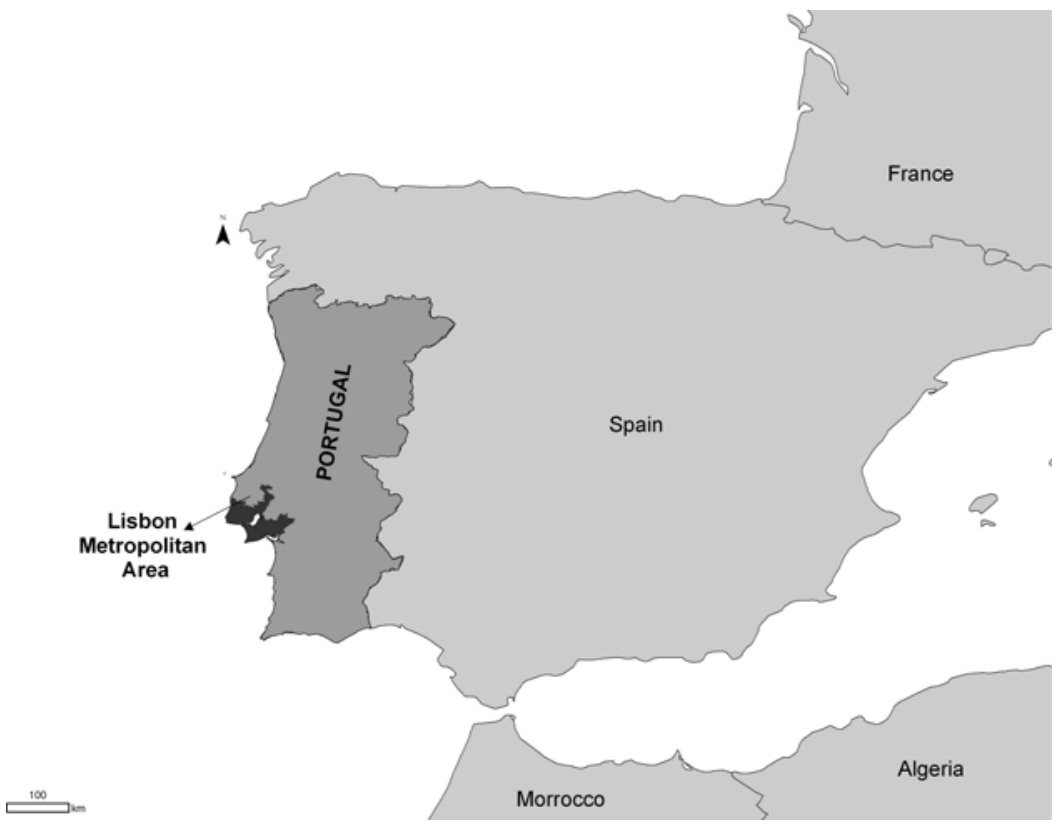

Fig. 1. Lisbon Metropolitan Area, Portugal

The 3,133- $\mathrm{km}^{2}$ area, comprising 19 municipalities and 216 neighbourhoods, includes some of Portugal's largest cities: Lisbon, Amadora, Cascais, Almada, Seixal and Setúbal. The LMA is wholly urban in nature, although a few of its parishes are still classified as rural. In 2011, $2,837,626$ people, $28.3 \%$ of Portugal's population, lived in the LMA, an increase of more than $3 \%$ from the time of the 2001 census. The LMA has some features that distinguish it from the rest of the nation: above-average population growth, mostly concentrated in the peripheral parishes; greater population mobility between peripheral and central areas (higher functional integration); higher levels of education and occupational status, mainly in the central areas; and greater purchasing power - the highest value nationally and far above the Portuguese average (in 2004, the national average was 100, while the LMA average was 116, and Lisbon's was 278) (Nogueira, 2007). Of Portugal's 21 healthy cities, 12 are located in LMA. Nonetheless, the region is plagued by social problems: high levels of poverty, deprivation and inadequate housing, mainly in inner-city areas; lack of resources, facilities and amenities, both in peripheral and central areas; low availability and use of public transport in the most peripheral, sprawling areas; and lower levels of social interaction and weak social networks, caused by the region's high level of residential mobility and by the persistent process of urbanisation (Nogueira, 2009).

\subsection{Individual variables}

All individual data were assessed from the National Health Survey (NHS) for the years 1998/1999. NHS has been carried out by governmental institutions since 1987 (1987, 1995/1996, 1998/99 and 2005/2006, the last with data of small areas not available) and is assessed by the National Center for Health Statistics of USA. NHS drew a random sample of 
21,808 households within small areas of the whole country, and 48,606 individuals were interviewed face-to-face by well-trained interviewers during 52 weeks. To the LMA, a representative sample composed by 9,846 individuals living in 143 neighbourhoods (of 216) was collected. From this sample, we selected only individuals aged 15 or over, because in these cases the responses to the inquiry are necessarily given by the individual him/herself (to individuals aged 14 years or younger, responses may be provided by relatives living in the household). Participants with missing data for variables used in the analysis were also excluded; the resulting study population comprised 5,004 individuals from 143 neighbourhoods.

The dependent variable was self-reported physical activity, measured as a binary response: whether the person engaged in or did not engage in physical activity. Individual predictors were age, sex, occupational class (manual, non-manual workers), economic activity (employed, unemployed, and other) education level (less than 4 years, between 5 and 12 years and more than 12 years), tobacco consumption and self-rated health (good/very good and less than good). There were 4,577 individuals in the final sample, of whom $60 \%$ were women, $55 \%$ were 35 to 64 years old, $67.3 \%$ reported sedentary behaviours, $60.5 \%$ rated their health as less than good, $44 \%$ had less than 4 years of education, $53.7 \%$ were manual workers and $21.8 \%$ were current smokers. All individual variables were included as dummy variables, except age, which was included as continuous.

\subsection{Local environment variables}

The generation of ecological data began with a consideration of what humans need in their local environments in order to lead healthy and active lives (Cummins et al., 2005). We listed 14 domains or constructs that described these needs: 1 . general aesthetics of the local area, 2. housing environment (indoor), 3. health services, 4 . leisure and recreation facilities, 5. sports facilities, 6. family support services, 7. street facilities, 8. house-keeping, 9. work and employment, 10. educational services, 11. crime and policing, 12. road safety, 13. public transport and 14. social capital and cohesion. At this stage, more than 240 contextual variables were assigned to the specified dimensions.

Contextual variables were obtained from a large range of routine and non-routine sources. These include the National Institute of Statistics (INE), local authorities, voluntary and public sector agencies (ministry of health, local and municipal police, the Portuguese social security), commercial organizations and others (the national institute of car insurance and yellow pages). Data refer to 2001-2005 and were collected at the neighbourhood level. We tried to generate accurate and specific contextual measures, beyond aggregate measures, since the latter generally do not reflect the underlying processes that link local environment to health (Cummins et al., 2005). The large amount of data created and assigned to the previously conceptualised domains, reflecting the local environment, had to be processed effectively. This was done using statistical methods following described.

\subsection{Statistics}

\subsubsection{Creating new environmental variables}

We collected a large amount of contextual data (246 variables) included in the 14 specified dimensions. Principal component analyses (PCAs) were performed to explore and reduce 
these data without losing information. All components (or factors) were rotated using varimax rotation to maximise factor loadings. Throughout the procedure, variables with low loadings onto components were discarded from the construct. Our aim was to create a single, strong component in each construct; components were rejected when considered irrelevant using Kaiser's criterion (dropping all those with eigenvalues less than 1.0) (Cummins et al., 2005; Nogueira, 2009). However, some domains revealed a bi-dimensional structure, which resulted in 19 extracted factors composed by 82 variables. These 19 factors, or components, were taken as local environment indicators.

The next step was to evaluate the internal consistency of the extracted factors and their ability to measure the latent contextual domains. Reliability was measured by standardised Alpha Scores, which ranged from 0.51 to 0.98 . These high values show that variables within each factor are strongly related, giving us confidence about the factors consistency. Moreover, correlations between the extracted factors were generally low, suggesting single and unambiguous factors, with the ability to reliably capture something unique about the local environment. Statistical analysis was performed using SPSS 17.0.

\subsubsection{Linking the neighbourhood environment to physical activity}

To examine the relationship between physical activity and individual and contextual attributes, we used the binary logistic regression model. We started with a simple model, considering individual factors as independent variables. In this model, we selected the variables with a conventional significance of $p \leq 0.05$. In a second stage, we extended the model by entering ecological variables when they were significant $(\mathrm{p} \leq 0.05)$. The final model was adjusted for all of the individual variables, and adjusted odds ratios (ORs) for environmental predictors were calculated. The level of statistical significance was set at 0.05 , and statistical analysis was performed using SPSS 17.0.

\section{Results}

The prevalence of sedentary behaviour in our sample was $67.3 \%$. This percentage was $89 \%$ among women and $31.5 \%$ among men. Table 1 shows the results from the binary logistic model predicting the likelihood of engaging in physical activity.

In our model, gender showed the biggest influence on physical activity, with women showing less physical activity than men (51\% less likely). Age was also found to have a detrimental effect; the odds of individuals reporting engagement in physical activity decreased by $15 \%$ with each additional 10 years in age. Individuals with lower levels of education were $24 \%$ less likely to be active, while having 13 or more years of education showed a beneficial effect, increasing by $40 \%$ the odds of active behaviour. Being in an occupation with manual labour also played a part, decreasing the odds of active behaviour by $31 \%$. Being employed had a negative effect, decreasing the odds of being physically active by $26 \%$. With regard to other health-related behaviours, smoking had a detrimental effect, with the odds of smokers being active decreasing by $24 \%$. Health status, assessed through self-rated health, also had an influence on likelihood of physical activity, and individuals who rated their health as good or very good were $49 \%$ more likely to report active behaviour. 


\begin{tabular}{|l|c|c|}
\hline \multicolumn{1}{|c|}{ Variables } & Coefficient & Adjusted Odd Ratios \\
\hline Sex (female vs. male) & -0.71 & $0.49^{* *}$ \\
\hline Age (in 10-year increments) & -0.016 & $0.85^{* *}$ \\
\hline $\begin{array}{l}\text { Occupation (manual worker vs. non- } \\
\text { manual) }\end{array}$ & -0.374 & $0.69^{* *}$ \\
\hline Education (<4 yrs vs. 5-12 yrs) & -0.277 & $0.76^{*}$ \\
\hline Education (13 + yrs vs. 5-12 yrs) & 0.335 & $1.40^{* *}$ \\
\hline $\begin{array}{l}\text { Health status (good/very good vs. } \\
\text { less than good) }\end{array}$ & 0.402 & $1.49^{* *}$ \\
\hline $\begin{array}{l}\text { Economic activity(employed vs. } \\
\text { unemployed) }\end{array}$ & -0.299 & $0.69^{* *}$ \\
\hline Tobacco (smoker vs. non-smoker) & -0.273 & $0.76^{* *}$ \\
\hline Public transport (less accessibility) & -0.167 & $0.85^{* *}$ \\
\hline Safety (more crime) & -0.124 & $0.88^{*}$ \\
\hline Health services (more availability) & 0.371 & $1.45^{* *}$ \\
\hline General aesthetics (worse quality) & -0.155 & $0.86^{*}$ \\
\hline Social relations (few interactions) & -0.23 & $0.79^{* *}$ \\
\hline
\end{tabular}

${ }^{*} \mathrm{p}<0.05 ;{ }^{* *} \mathrm{p}<0.001$

Table. 1. Coefficients, odd ratios and significance levels from a multiple binary logistic regression model predicting active behaviours in the LMA.

As for neighbourhood conditions, after controlling for all of the individual variables presented in table 1, a significant association was found between physical activity and public transport accessibility, neighbourhood safety, availability of health services, general aesthetics of living local area and level of social interactions. Considering variations of one standard deviation, we concluded that individuals living in areas with lower levels of public transport accessibility were $15 \%$ less likely to report an active behaviour. Those living in unsafe areas, with high levels of crime, were $12 \%$ less likely to practice physical activity. Living in areas with greater availability of health services increase the odds of being active by $45 \%$. A positive association between general aesthetics of the residential area and physical activity was also confirmed, with the odds of being active decreasing by $14 \%$ in areas that are considered unpleasant. Social relations showed a similar influence. Individuals living in areas in which social interactions are scare were $21 \%$ less likely to report active behaviour.

\section{Discussion}

This research presents several important findings that contribute to our understanding of physical activity behaviour. Variations in levels of physical activity arise from individual characteristics such as gender, age, socioeconomic, health-related behaviours (such as 
smoking) and health status. However, location also plays a role in active living, and our results show that built and social environments are key focal points. The LMA is a rapidly growing region with a diverse population, in which the creation of environments conducive to physical activity depend upon adequate public transport systems, mixed land-use patterns, convenient social environments (safe places with social interactions that provide opportunities to be active) and neighbourhood aesthetics.

In terms of the physical environment, our results from Lisbon, which highlight the availability of health services, general aesthetics and accessibility of public transport as determinants of physical activity, are consistent with previous research. Mixed land-use e.g., provision of and access to local public services and facilities - and attractive scenery have been found to be associated with higher physical activity levels (Frank et al., 2006; Stafford et al., 2007). Areas with higher diversity and population density, often involving designs that incorporate connected streets, sidewalks and bicycle paths, have been found to be more walkable (Doyle et al., 2006). Authors have also suggested the importance of commuting by public transportation, and of walking or cycling to and from public transport, in helping people to attain recommended levels of daily physical activity (Besser \& Dannenberg, 2005; Zheng, 2008). Results in the LMA showed that making public transport accessible and providing more opportunities for active travel may promote and help people maintain active lifestyles. Physical neighbourhood features that can promote active behaviour typically have been summarised by the expression "walkable neighbourhood", which is defined as an area that combines several features: density, land use, street connectivity, transportation, attractiveness and general aesthetics (Calthorpe \& Fulton 2001; Jochelson, 2004; Doyle et al., 2006; Frank et al., 2006; Stafford et al., 2007).

Our model also highlighted social and psychosocial factors, corroborating earlier results. Violence, social disorder and the feeling of fear inhibit social interactions and lead people to limit their outdoor physical activity (Parkes and Kearns, 2006). Poortinga (2006) found positive associations between social support, social capital and higher levels of physical activity, and Cohen et al. (2006) suggested a positive effect of social cohesion among neighbours in various positive health behaviours, including physical activity. Van Lenthe et al. (2005) stressed the role of neighbourhood attractiveness and safety in encouraging physical activity. In the LMA, people living in disadvantageous social environments in which violence is prevalent likely decrease their level of social interaction, consequently decreasing their level of social capital and social cohesion. As a result, social isolation, insecurity, anxiety, stress, depression and hopelessness increase, which may decrease individuals' willing to engage in physical activity (Wilkinson, 1999).

\subsection{Study weakness}

A major limitation of this study is the cross-sectional nature of the data which prevents an exploration into causal relationships. Just because an association was observed, it does not mean causation; we can only argue that these results show a jointed variation of physical activity and some, specific, neighbourhood features. Another limitation is that other important covariates, not considered in our model, may explain the associations. For example, body mass index may be an important determinant of physical activity. It is also important to note that physical activity was self-reported, thus subject to bias. 


\section{Conclusion}

Individuals living in neighbourhoods that are socially and physically disadvantageous are at increased risk of engaging in sedentary behaviour. Local environmental features contribute to the growing rates of physical inactivity and obesity among people living in the LMA. Creating a high-quality developed environment that is walkable, safe and supportive of social interaction would increase opportunities for physical activity and improve the health of all inhabitants. But how do we accomplish this goal?

As empirical evidence on active living environments accumulates, there should be more efforts to translate research into practice. Considering the growing levels of inactivity and obesity of modern societies, and in light of the multiple, diverse features required for an environment that can promote active living, we propose the creation of an interdisciplinary team that can work toward better places and better health: a Task Force for Active Living Environments. The work of the task force would be rooted in empirical evidence. Policymakers, urban planners, transportations engineers and public health workers would cooperate in order to improve the quality of the local area - its safety, urban design, land use, public transport, social organisation and general aesthetics - and ensure that it provides opportunities for physical activity. Planning that promotes and supports behavioural change is only possible through cooperation from all sectors involved in helping activeliving environments to emerge.

Finally, we can suggest a variation on our initial approach. If improvements to the local environment can increase physical activity, increased physical activity can also improve the local environment. Active people change their neighbourhoods by creating more cohesive communities, strengthening social bonds and increasing social control - in short, shaping safer and more pleasant areas. In this sense, walkability is more than just a form of community. It is a way of life, one that is healthier, more ecologically sound and more neighbourhood-friendly.

\section{References}

ACPHHS (2005). The Integrated Pan-Canadian Healthy Living Strategy, Advisory Committee on Population Health and Health Security, ISBN 0-662-69384-1, Canada.

ACS (2008). Plano Nacional de Saúde: Indicadores e Metas do PNS. In: Ministério da Saúde Alto Comissariado da Saúde, 3.01.2008, Available from http://www.acs.minsaude.pt/pns/.

Besser, L. \& Dannenberg, A. (2005). Walking to Public Transit Steps to Help Meet Physical Activity Recommendations. American Journal of Preventive Medicine, Vol. 29, No 4, pp. 273-280.

Burdette A. \& Hill, T. (2008). An examination of processes linking perceived neighborhood disorder and obesity. Social Science \& Medicine, Vol. 67, pp. 38-46.

Calthorpe, P. \& Fulton, W. (2001). The regional City. Planning for the End of Sprawl, Island Press, Washington.

Catlin, T.; Simoes, E., \& Brownson, R. (2003). Environmental and policy factors associated with overweight among adults in Missouri. American Journal of Health Promotion, Vol. 17, No. 4, pp. 249-258. 
Cerin, E.; Leslie, E.; du Toit, L.; Owen, N. \& Frank LD. (2007). Destinations that matter: associations with walking for transport. Health \& Place, Vol. 13, No. 3, pp. 713-724.

Cohen, D.; Finch, B.; Bower, A., \& Sastry, N. (2006). Collective efficacy and obesity: The potential influence of social factors on health. Social Science \& Medicine, Vol. 62, No. 3, pp. 769-778.

Cummins, S.; Macintyre, S.; Davidson, S. \& Ellaway, A. (2005). Measuring neighbourhood social and material context: generation and interpretation of ecological data from routine and non-routine sources. Health $\mathcal{E}$ Place, Vol. 11, No. 3, pp. 249-260.

Demarest S.; Cox B., Van Oyen H. (2007), Socio economic inequalities in leisure time physical activity: results of the EUROTHINE project. Scientific Institute of Public Health, Belgium, Brussels.

Doyle, S.; Kelly-Schawartz, A.; Scholossberg, M. \& Stockard, J. (2006). Active community environments and health: the relationship of walkable and safe communities to individual health. Journal of the American Planning Association, Vol. I, pp. 19-31.

Finucane, M; Stevens, G.; Cowan, M.; Danaei, F.; Lin, J.; Paciorek, C.; Singh, G.; Gutierrez, H.; Lu, Y.; Bahalim, A.; Farzadfar, F.; Riley, L. \& Ezzati, M. (2011). National, regional, and global trends in body-mass index since 1980: systematic analysis of health examination surveys and epidemiological studies with 960 country-years and 9.1 million participants. Lancet, Vol. 377, pp. 557-567.

Frank, L.; Andresen, M.; \& Schmid, T. (2004). Obesity relationships with community design, physical activity, and time spend in cars. American Journal of Preventive Medicine, Vol. 27, No. 2, pp. 87-96.

Frank, L.; Kerr, J., Chapman, J. \& Sallis, J.(2007). Urban form relationships with walk trip frequency and distance among youth. American Journal of Health Promotion, Vol. 21, No. 4, pp. 305-311.

Frank, L.; Sallis, J.; Conway, T.; Chapman, J.; Saelens, B. \& Bachman, W. (2006). Many pathways from land use of health: associations between neighbourhood walkability and active transportation, body mass index, and air quality. Journal of the American Planning Association, Vol. I, pp. 75-87.

Giles-Corti, B., \& Donovan, R. (2003). Relative influences of individual, social environmental, and physical environmental correlates of walking. American Journal of Public Health, Vol. 93, pp. 1583-1589.

Jen, M.; Jones, K. \& Johnston, R. (2009). Compositional and contextual approaches to the study of health behaviour and outcomes: Using multi-level modeling to evaluate Wilkinson's income inequalities hypothesis. Health E Place, Vol. 15, pp. 198-203.

Jochelson, K. (2004). The Public Health Impact of Cities \& Urban Planning. Report. London Development Agency: King's Fund, London.

Kamphius, A.; Van Lenthe, F.; Giskes, K.; Brug, J. \& Mackenbach, J. ( 2007). Perceived environmental determinants of physical activity and fruit and vegetable consumption among high and low socioeconomic groups in the Netherlands. Health \& Place, Vol. 13, pp. 493-503.

Kim, D.; Subramanian, S.; Gortmaker, S. \& Kawachi, I. (2006). US State-and county- level social capital in relation to obesity and physical inactivity: a multilevel, multivariable analysis. Social Science \& Medicine, Vol. 63, pp. 1045-1059. 
Leslie, E.; Coffee, N.; Frank, L.; Owen, N.; Bauman, A. \& Hugo, G. (2007). Walkability of local communities: using geographical information systems to objectively assess relevant environmental attributes. Health \& Place, Vol. 13, pp. 111-122.

Maddison, R.; Hoorn, S.; Jiang, Y.; Mhurchu, C.; Exeter, D.; Dorey, E.; Bullen, C.; Utter, J.; Scaaf, D. \& Turley, M. (2009). The environment and physical activity: The influence of psychosocial, perceived and built environment factors. International Journal of Behavioral Nutrition and Physical Activity, Vol. 6, No. 19, doi: 1186/14795868-6-19.

McNeill, L.; Kreuter, M. \& Subramanian, S. (2006). Social environment and physical activity: a review of concepts and evidence. Social Science \& Medicine, Vol. 63, pp. 1011-1022.

Mladovsky, P.; Allin, S.; Masseria, C.; Hernández-Quevedo, C.; McDaid, D.; Mossialos, E. (2009), Health in the European Union. Trends and analysis. European Observatory on Health Systems and Policies, WHO Regional Office for Europe, Copenhagen.

Nogueira, H. (2007). Os Lugares e a saúde. Uma abordagem da Geografia às variações em saúde na Área Metropolinada de Lisboa. Ph.D. Unpublished Thesis, University of Coimbra, Coimbra.

Nogueira, H. (2009). Healthy communities: the challenge of social capital in the Lisbon Metropolitan Area. Health E Place, Vol. 15, pp. 133-139.

Nusselder, W.; Looman, C.; Franco, O.; Peeters, A.; Slingerlan, A. \& Mackenbach, J. (2008). The relation between non-occupational physical activity and years lived with and without disability. Journal of Epidemiology and Community Health, Vol. 62, No. 9, pp. 823-828.

Padez, C.; Fernandes, T.; Mourão, I.; Moreira, P. \& Rosado, V. (2004). Prevalence of overweight and obesity in 7-9-year-old Portuguese children: Trends in body mass index from 1970-2002. American Journal of Human Biology, Vol. 16, pp. 670-678.

Parkes, A. \& Kearns, A. (2006). The multi-dimensional neighbourhood and health: a crosssectional analysis of the Scottish Housing Survey, 2001. Health E Place, Vol. 12, No. 1, pp. 1-18.

Poortinga, W. (2006). Perceptions of the Environment, Physical Activity, and Obesity. Social Science \& Medicine, Vol. 63, pp. 2835-2846.

Stafford, M.; Cummins, S.; Ellaway, A.; Sacker, A.; Wiggins, R. D. \& Macintyre, S. (2007). Pathways to obesity: identifying local, modifiable determinants of physical activity and diet. Social Science \& Medicine, Vol. 65, pp. 1882-1897.

Van Lenthe, F.; Brug, J. \& Mackenbach, J. (2005). Neighborhood inequalities in physical inactivity: the role of neighborhood attractiveness, proximity to local facilities and safety in the Netherlands. Social Science \& Medicine, Vol. 60, pp. 763-775.

WHO (2002). World Health Report, Reducing risks, promoting healthy life. World Health Organization, Geneva.

WHO Regional Office for Europe (2007). The challenge of obesity in the WHO European Region and the strategies for response, WHO Regional Office for Europe, ISBN 978-92-8901388-8, Copenhagen.

Wilkinson R (1999). Putting the picture together: Prosperity, redistribution, health and welfare, In: Social determinants of health, M. Marmot \& Wilkinson RG (eds), pp. 256274, Oxford University, Oxford. 
Wilkinson R, Marmot M (2003). Social determinants of health: The solid facts. Second edition. WHO Regional Office for Europe, Copenhagen.

Zheng, Y. (2008). The benefit of public transportation: Physical activity to reduce obesityand ecological footprint. Preventive Medicine, Vol. 46, pp. 4-5. 


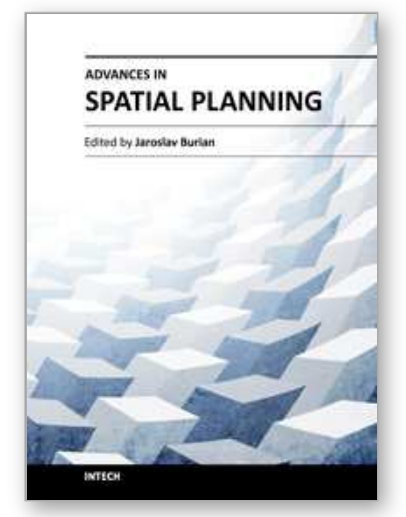

\author{
Advances in Spatial Planning \\ Edited by Dr Jaroslav Burian
}

ISBN 978-953-51-0377-6

Hard cover, 366 pages

Publisher InTech

Published online 21, March, 2012

Published in print edition March, 2012

Spatial planning is a significant part of geosciences that is developing very rapidly. Many new methods and modeling techniques like GIS (Geographical Information Systems), GPS (Global Positioning Systems) or remote sensing techniques have been developed and applied in various aspects of spatial planning. The chapters collected in this book present an excellent profile of the current state of theories, data, analysis methods and modeling techniques used in several case studies. The book is divided into three main parts (Theoretical aspects of spatial planning, Quantitative and computer spatial planning methods and Practical applications of spatial planning) that cover the latest advances in urban, city and spatial planning. The book also shows different aspects of spatial planning and different approaches to case studies in several countries.

\title{
How to reference
}

In order to correctly reference this scholarly work, feel free to copy and paste the following:

Helena Nogueira, Cristina Padez and Maria Miguel Ferrão (2012). Healthy Places, Healthy People: Living Environment Factors Associated with Physical Activity in Urban Areas, Advances in Spatial Planning, Dr Jaroslav Burian (Ed.), ISBN: 978-953-51-0377-6, InTech, Available from:

http://www.intechopen.com/books/advances-in-spatial-planning/healthy-places-healthy-people-livingenvironment-factors-associated-with-physical-activity-in-urban-

\section{INTECH}

open science | open minds

\author{
InTech Europe \\ University Campus STeP Ri \\ Slavka Krautzeka 83/A \\ 51000 Rijeka, Croatia \\ Phone: +385 (51) 770447 \\ Fax: +385 (51) 686166 \\ www.intechopen.com
}

\author{
InTech China \\ Unit 405, Office Block, Hotel Equatorial Shanghai \\ No.65, Yan An Road (West), Shanghai, 200040, China \\ 中国上海市延安西路 65 号上海国际贵都大饭店办公楼 405 单元 \\ Phone: +86-21-62489820 \\ Fax: +86-21-62489821
}


(C) 2012 The Author(s). Licensee IntechOpen. This is an open access article distributed under the terms of the Creative Commons Attribution 3.0 License, which permits unrestricted use, distribution, and reproduction in any medium, provided the original work is properly cited. 